\title{
The Antitumor Activity of Meconopsis Horridula Hook, a Traditional Tibetan Medical Plant, in Murine Leukemia L1210 Cells
}

\author{
Jianping Fan a,b Yaqin Wang ${ }^{\mathrm{a}}$ Xiaobing Wanga Pan Wang ${ }^{\mathrm{a}}$ Wei Tang ${ }^{\mathrm{a}}$ \\ Wenjuan Yuan ${ }^{\mathrm{a}}$ Lulu Kong ${ }^{\mathrm{a}}$ Quanhong Liu ${ }^{\mathrm{a}}$
}

\begin{abstract}
aKey Laboratory of Medicinal Resources and Natural Pharmaceutical Chemistry, Ministry of Education, National Engineering Laboratory for Resource Developing of Endangered Chinese Crude Drugs in Northwest of China, College of Life Sciences, Shaanxi Normal University, Shaanxi, ${ }^{b}$ College of Life Sciences, Qinghai Normal University, XiNing, China
\end{abstract}

\author{
Key Words \\ M. horridula • L1210 cells • Apoptosis • Cell cycle arrest • ROS
}

\begin{abstract}
Background: Meconopsis horridula Hook (M. horridula) has been used as a traditional Tibetan medicine to relieve heat and pain as well as mobilize static blood, and it is recognized as a good treatment for bruises. This study is the first trial to evaluate the tumor inhibitory activity of $M$. horridula extract and its underlying mechanism in the hope of providing evidence to support the anticancer function of M. horridula. Methods and Results: M. horridula extract was cytotoxic to L1210 cells in a dose- and time-dependent manner. SEM (scanning electron microscope) observation revealed obvious morphological changes in L1210 cells after M. horridula treatment. Flow cytometry analysis demonstrated that the extract dose-dependently induced early apoptosis. Additional apoptosis parameters, such as alterations in nuclear morphology and DNA damage, were also observed. Furthermore, M. horridula treatment induced G2/M arrest. M. horridula treatment significantly increased reactive oxygen species (ROS) production, suggesting that ROS are a key factor in M. horridula-induced apoptosis. Volatile constituent detection found 15 abundant chemicals in M. horridula, which may contribute to its anticancer effect. Conclusion: In conclusion, M. horridula extract induced L1210 cell apoptosis and inhibited proliferation through G2/M phase arrest, and ROS were involved in the process.
\end{abstract}




\section{Introduction}

Leukemia and lymphoma are a group of heterogeneous neoplastic white blood cell disorders characterized by uncontrolled proliferation and blocked differentiation of hematopoietic cells [1]. According to the WHO, leukemia and lymphomas are the fifth leading cause of cancer death worldwide [2]. The current conventional treatment for leukemia involves radiotherapy, chemotherapy, hormonal therapy, immune therapy and symptomatic and supportive therapy. However, conventional chemotherapy drugs, such as 5-fluorouracil, doxorubicin and Paclitaxel, produce severe side effect for patients. Therefore, there is an increasing interest in therapy with drugs of plant origin [3]. Natural products such as traditional Chinese herbal medicines provide a promising approach for cancer treatment because of their low toxicity against normal cells and potential effectiveness against cancer cells [4].

Tibetan medicine is a component of the most important ethnic drugs in traditional Chinese medicine, and it is very popular worldwide, especially in India and Europe. Meconopsis, an endangered genus of ornamental flowers, belongs to the Papaveraceae family. It has been used as the medicine for hundreds of years in Tibet [5]. The Meconopsis genus comprises approximately 50 species, and 43 species are primarily distributed throughout the Qinghai-Tibetan Plateau (QPT) and the neighboring mountains, except a few that inhabit Europe [6,7]. The Meconopsis species is attractive for scholars because of its beautiful flowers and medicinal functions. Some Meconopsis species have reported anti-inflammatory and antioxidant effects $[8,9]$.

Meconopsis horridula is a perennial herb with sharp spines on its leaves and stems and is one of the most widely distributed species of the Meconopsis genus. It is scattered on grassy or rocky slopes at altitudes of 3000-4900 m in southwestern China [10]. For hundreds of years, $M$. horridula has been used as a traditional Tibetan medicine to clear away heat, relieve pain, mobilize static blood, and to treat bruises [11]. Modern pharmacological studies have demonstrated that $M$. horridula has sedative, anti-inflammatory and anti-Shigella activities [12]. M. horridula is usually constituted in herbal combination remedies for treating osteomyelitis and liver disease, such as Bawei Qinpi Pills, Ershiwuwei Luronghao ills, and Ganluling Pills. In addition, alkaloids, flavonoids, and phenylpropanoids are reportedly abundant in Meconopsis species, including M. horridula $[13,14]$. Several of these compounds have been shown to exert anticancer functions, suggesting that $M$. horridula may also have anti-cancer effects. We previously examined 4 Meconopsis species, including Meconopsis racemosa, Meconopsis integrifolia, Meconopsis punicea and Meconopsis horridula, to test their anti-cancer effects by MTT assays, and the data suggested that $M$. horridula was the most efficient (data not shown). This study is the first attempt to evaluate the tumor inhibition activity of $M$. horridula extract and its underlying mechanism.

Apoptosis is programmed cell death characterized by DNA degradation, chromatin condensation, and nuclear fragmentation [15], and it plays an important role in tissue homeostasis and development [16]. Apoptosis deregulation is important in cancer initiation and progression $[15,17]$. Therefore, cancer cell apoptosis induction has long been regarded an important target in cancer treatment.

Reactive oxygen species (ROS) is a key apoptosis induction factor. Many natural products have been reported to inhibit cancer cell proliferation by increasing intracellular ROS level. For instance, Fomitopsis pinicola chloroform extract induced SW-480 cell apoptosis by increasing ROS accumulation [18]. Acidic PAP-3 (a polysaccharide) has also been shown to exert anti-cancer effects through the ROS-mediated mitochondrial apoptotic pathway [19]. In this study, we examined the pro-apoptotic effects of $M$. horridula extract and the role of ROS.

The weakly immunogenic L1210 cell line is similar to the human leukemia condition and is a typical cell modal to study the anti-cancer effects of several natural products [20]. In our study, we used L1210 cells to evaluate the anti-cancer effects of M. horridula extract. 


\section{Cellular Physiology Cell Physiol Biochem 2015;37:1055-1065

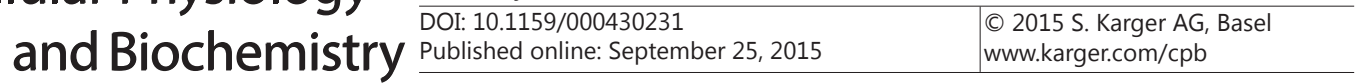

Fan et al.: M. Horridula Triggers L1210 Cells Apoptosis and G2/M Phase Arrest

\section{Materials and Methods}

Preparation of M. horridula ethanol extracts

The fresh M. horridula plants were collected in Yushu County, Tibetan Autonomous Prefecture of Yushu Qinghai Province in August 2011 (altitude 4639m). The plant species identities were authenticated by Associate Prof Jun-Hua Du at School of Life and Geographical Sciences, Qinghai Normal University.

Dried M. horridula powder was homogenized in $95 \%$ ethanol at $45^{\circ} \mathrm{C}$, using ultrasonic-assisted extraction (UAE) three times. The ethanol extract was obtained from vacuum filter and then the supernatant was collected and concentrated with a rotary evaporator (RE-2000 A; Belong, Shanghai, China). The ethanol fraction was homogenized in $70 \%$ ethanol and the supernatant was filtered using $0.22 \mu \mathrm{m}$ filters.

\section{GC-MS instrument and analytical conditions}

To investigate the composition of $M$. horridula extract, GC-MS analysis was performed with a 7890A GC/5975C MS system (Agilent, USA) fitted with a fused silica capillary column (HP-5 MS, $30 \mathrm{~m} \times 25 \mathrm{~mm}$ ID, $0.25 \mu \mathrm{m}$ film thickness; Agilent J\&W Scientific, Folsom, CA, USA). One microliter of the sample was analyzed, with a split ratio of $10: 1(\mathrm{v} / \mathrm{v})$. The temperature rise program had an initial temperature of $50{ }^{\circ} \mathrm{C}$ for $2 \mathrm{~min}$, which was raised $10{ }^{\circ} \mathrm{C} / \mathrm{min}$ to $200{ }^{\circ} \mathrm{C}$ and then maintained for $2 \mathrm{~min}$; raised to $250{ }^{\circ} \mathrm{C}$ at $5{ }^{\circ} \mathrm{C} / \mathrm{min}$ and then maintained for $6 \mathrm{~min}$; and raised to $280^{\circ} \mathrm{C}$ at $10^{\circ} \mathrm{C} / \mathrm{min}$ and isothermally maintained for $5 \mathrm{~min}$. The injector temperature was set to $280{ }^{\circ} \mathrm{C}$ and the interface temperature was $150{ }^{\circ} \mathrm{C}$. The Helium MS source was used as the carrier gas at a flow rate of $1 \mathrm{ml} / \mathrm{min}$. The ionization source temperature was $250^{\circ} \mathrm{C}$. Mass spectrometry was determined by the full-scan method, ranging from 50 to 600 (m/z). Metabolites were identified by comparison with the NIST Mass Spectral Search Program 2008 database (version 2.0, FairCom Co., Columbia, MO, USA).

\section{Cell cultures}

Murine leukemia L1210 cells were purchased from the American type culture collection (CCL ${ }^{-219 T M}$, ATCC). Cells were cultured under standard conditions in DMEM medium (Sigma-Aldrich) supplemented with $10 \%(\mathrm{v} / \mathrm{v}$ ) 10\% heat-inactivated horse serum (Gibco/Invitrogen, Carlsbad, CA, USA), $100 \mathrm{U} / \mathrm{ml}$ penicillinstreptomycin solution (Hyclone, Logan, UT, USA) and $1 \mathrm{mM}$ L-glutamine (Sigma-Aldrich), routinely subcultured every day, and incubated at $37^{\circ} \mathrm{C}$ in humidified atmosphere with a $5 \% \mathrm{CO}_{2}$ incubator.

\section{Cell viability assay}

The effect of $M$. horridula extract on L1210 cell viability was determined with the conventional MTT (Sigma, St Louis, USA) reduction assay [18]. Briefly, $100 \mu \mathrm{L} \mathrm{L1210} \mathrm{cell} \mathrm{suspension} \mathrm{was} \mathrm{placed} \mathrm{in} \mathrm{a} \mathrm{96-well}$ culture plate at a density of $1 \times 10^{5}$ cells $/ \mathrm{mL}$ and incubated with various concentrations of M. horridula $(0$, $30,60,90$ and $120 \mu \mathrm{g} / \mathrm{mL}$ ) extract for distinct time points ( $24 \mathrm{~h}$ and $48 \mathrm{~h}$ ). The treated cells were incubated with MTT solution, and the formazan crystals were dissolved in $100 \mu \mathrm{L} \mathrm{10 \%} \mathrm{SDS,} \mathrm{5 \%} \mathrm{isobutanol} \mathrm{and} 0.01 \mathrm{M}$ HCL solution. Absorbance at $570 \mathrm{~nm}$ was recorded with a microplate reader (ELX800; BIO-TEK, Winooski, VT, USA). The cell viability of treated samples was obtained by comparison with the untreated control.

PBMCs (peripheral blood mononuclear cells) were used to evaluate the cytotoxicity of M. horridula extract on normal cells. PBMCs were isolated using a lymphocyte separation kit (Applygen Technologies Inc., Beijing, China) according to the manufacturer's protocol. Briefly, separation liquid was immediately added to blood collected from a mouse, and the sample was centrifuged at $800 \mathrm{~g}$ for $30 \mathrm{~min}$. The middle fraction was collected as PBMCs. PBMCs were treated with different dosages of M. horridula extract $(0,100$, 200 and $300 \mu \mathrm{g} / \mathrm{ml}$, or $70 \%$ ethanol as the solvent control) for 24 or $48 \mathrm{~h}$. PBMC viability was assessed using a trypan blue exclusion test.

\section{Scanning electron microscopy (SEM) observation}

After $24 \mathrm{~h}$ following various concentrations of $M$. horridula extract $(0,60,90$ and $120 \mu \mathrm{g} / \mathrm{ml})$, cells in each group were fixed by $2.5 \%$ glutaraldehyde, washed by PBS, dehydrated by graded alcohol, displaced, dried at the critical point, gold evaporated, and finally observed under a SEM (S-3400N, Hitachi, Tokyo, Japan). 
Hoechst 33342 staining

Hoechst 33342 (HO) is a fluorescent probe that binds to double-stranded DNA and represents changes in nuclear morphology. To examine whether M. horridula treatment induced nuclear changes in L1210 cells, HO staining was performed. After M. horridula extract $(0,60,90,120 \mu \mathrm{g} / \mathrm{ml})$ treatment for 12,24 or $48 \mathrm{~h}$, cells were stained with $10 \mu \mathrm{M}$ HO for $15 \mathrm{~min}$ at room temperature. The stained cells were washed three times with PBS and observed by fluorescence microscopy with standard excitation filters (Nikon E-600, Japan).

\section{Apoptosis detection by flow cytometry}

Apoptotic cells were quantified with an Annexin V-FITC Apoptosis Detection Kit (Invitrogen, USA) according to the manufacturer's protocol. Briefly, $1 \times 10^{5} \mathrm{cells} / \mathrm{ml}$ were treated with various concentrations $(0,60,90$ and $120 \mu \mathrm{g} / \mathrm{mL})$ of $M$. horridula extract for $12 \mathrm{~h}$ at $37^{\circ} \mathrm{C}$. The cells were then harvested and resuspended in binding buffer. They were stained with $10 \mu \mathrm{l}$ Annexin V-FITC and $5 \mu \mathrm{L}$ PI for $15 \mathrm{~min}$ at room temperature in the dark. The apoptotic index was immediately determined by flow cytometry (Guava easy Cyte 8HT, Millipore, Billerica, MA, USA).

\section{Cell cycle analysis}

The ratio of cells in the G1, S, and G2/M phases of the cell cycle was determined by their DNA content. Cells at $1 \times 10^{5}$ cells $/ \mathrm{ml}$ were treated with various concentrations $(0,60,90,120 \mu \mathrm{g} / \mathrm{mL})$ of M. horridula extract for $72 \mathrm{~h}$. Cells were harvested and washed twice with cold PBS and fixed with $70 \%$ ice-cold ethanol at $4^{\circ} \mathrm{C}$ overnight. The fixed cells were washed twice with cold PBS and incubated with $100 \mu \mathrm{g} / \mathrm{ml}$ RNase A (Sigma, St. Louis, USA) for $30 \mathrm{~min}$ at $37^{\circ} \mathrm{C}$, then stained with $50 \mu \mathrm{g} / \mathrm{ml}$ propidium iodide (PI; Sigma, St. Louis, USA) for $30 \mathrm{~min}$ in the dark and analyzed by flow cytometry (Millipore, USA).

\section{DNA fragmentation assay}

Krysko et al. [21] described an easy and quantitative way to analyze DNA fragmentation which is based on flow cytometric detection of DNA hypoploidy after adding PI to the dying cells and permeabilizing them by freeze-thawing. The size of DNA fragments appeared as a hypoploid DNA histogram. To investigate the effect of M. horridula extract on DNA damage of L1210 cells, oligonucleosomal DNA fragmentation by flow fluorocytometry was performed. Cells were treated with various concentrations $(0,60,90,120 \mu \mathrm{g} / \mathrm{mL})$ of M. horridula extract for 12 and $24 \mathrm{~h}$, then they were stained with $5 \mu \mathrm{g} / \mathrm{ml} \mathrm{PI}$ and freeze-thawed for $30 \mathrm{~s}$. Cells were immediately analyzed by flow cytometry.

\section{Intracellular reactive oxygen species detection}

The intracellular ROS level was evaluated by the oxidative conversion of $2^{\prime}, 7^{\prime}$-dichlorofluoresceindiacetate (DCFH-DA) to fluorescent 2', 7'-dichlorofluorescein (DCF) [18]. L1210 cells were treated with the mentioned concentrations of $M$. horridula extract for 2 and $6 \mathrm{~h}$. The treated cells were harvested, washed twice with PBS, re-suspended in $500 \mu \mathrm{l}$ of $10 \mu \mathrm{M}$ DCFH-DA (Molecular Probes Inc., Invitrogen, CA, USA) and incubated at $37^{\circ} \mathrm{C}$ for $30 \mathrm{~min}$ in the dark. The samples were then immediately detected by flow cytometry. Histograms were analyzed using FCS Express V3.

\section{Statistical analysis}

All the experiments were performed in triplicate, and data were expressed as means $\pm \mathrm{SD}$. $\mathrm{IC}_{50}$ values were calculated by regression analysis. The data were subjected to an analysis of Duncan's multiple range tests (SPSS, version 18.0). A significant difference was judged to exist at a level of * $p<0.05$ and $^{* *} p<0.01$.

\section{Results}

\section{GC-MS analysis for M. horridula extract}

We used GC-MS assay to analyze the volatile constituents of $M$. horridula extract. We considered compounds to be "identified" when their mass spectral fit values were at the default value of $90 \%$ or above. As shown in Table 1, we identified a total of 15 constituents in the extract. 
Fan et al.: M. Horridula Triggers L1210 Cells Apoptosis and G2/M Phase Arrest

Table 1. Identification of M. horridula extract metabolites using GC-MS analysis

\begin{tabular}{lclc}
\hline Number & $\begin{array}{c}\text { Retention time } \\
(\mathrm{min})\end{array}$ & Chemical Terms & $\begin{array}{c}\text { Density } \\
(\%)\end{array}$ \\
\hline 1 & 8.661 & Methoxyphenol & 1.47 \\
2 & 12.014 & 2-Methoxy-4-vinylphenol & 0.56 \\
3 & 12.502 & Phenol, 2,6-dimethoxy & 0.51 \\
4 & 17.219 & 4-((1E)-3-Hydroxy-1-propenyl)-2-methoxyphenol & 1.27 \\
5 & 18.857 & Phthalic acid, isobutyl octyl ester & 0.36 \\
6 & 20.177 & n-Hexadecanoic acid & 7.95 \\
7 & 23.067 & 9,12 -Octadecadienoic acid (Z,Z) & 38.08 \\
8 & 23.142 & $9,17-$ Octadecadienal, (Z) & 17.97 \\
9 & 23.468 & Octadecanoic acid & 1.45 \\
10 & 23.505 & Linoleic acid ethyl ester & 1.02 \\
11 & 25.701 & 7-Pentadecyne & 0.12 \\
12 & 26.733 & Eicosanoic acid & 0.41 \\
13 & 28.466 & Butyl 9,12-octadecadienoate & 0.12 \\
14 & 30.023 & gamma-Sitosterol & 7.37 \\
15 & 32.281 & 7-Pentadecyne & 0.45 \\
\hline
\end{tabular}
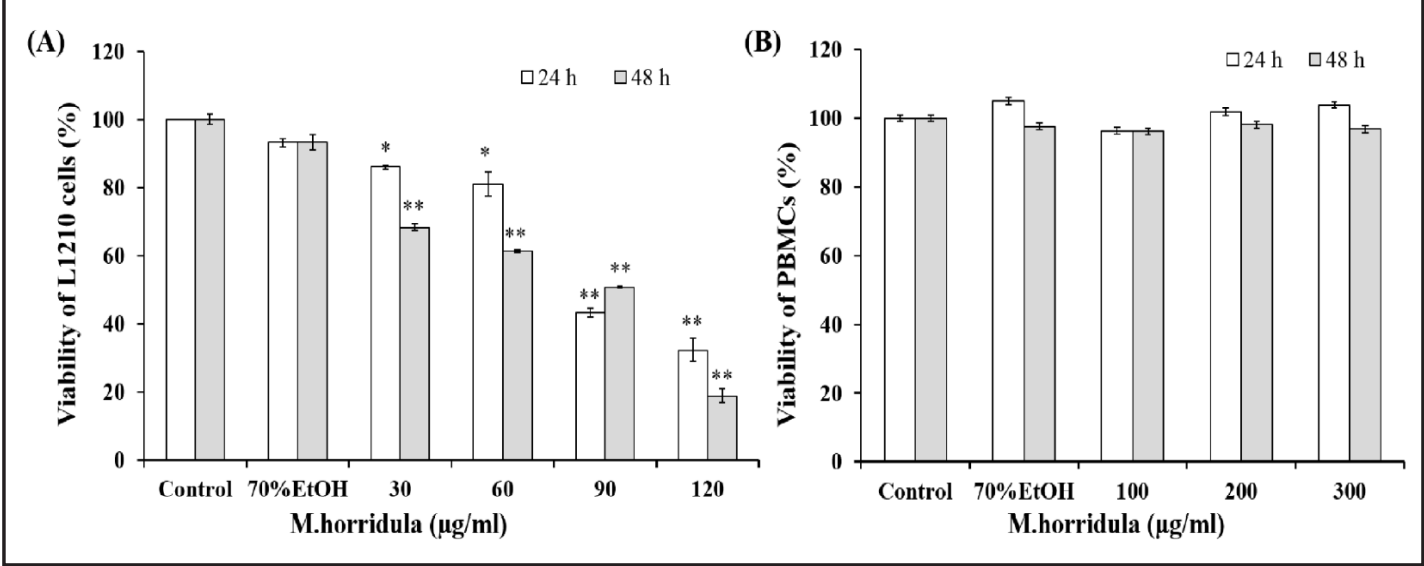

Fig. 1. Effects of $M$. horridula ethanol extract on cell viability. (A) L1210 cell viability was measured by MTT assay. (B)The cell viability of PBMCs was evaluated by trypan blue assay. Each value was expressed as a mean \pm S.D. of at least three independent determinations. One-way ANOVA was used for comparisons of multiple group means followed by Dunnett's t-test. ${ }^{*} \mathrm{p}<0.05$ and ${ }^{* *} \mathrm{p}<0.01$ versus control.

\section{Cytotoxicity of M. horridula}

As shown in Fig. 1A, L1210 cell viability was $81.9 \pm 3.6 \%(* \mathrm{p}<0.05)$ after treatment with $60 \mu \mathrm{g} / \mathrm{mL}$ M. horridula for $24 \mathrm{~h}$. As the dose increased from 90 to $120 \mu \mathrm{g} / \mathrm{ml}$, cell viability decreased from $56.6 \pm 1.3 \%\left({ }^{* *} \mathrm{p}<0.01\right)$ to $67.8 \pm 3.3 \%\left({ }^{* *} \mathrm{p}<0.01\right)$. We calculated the $\mathrm{IC}_{50}$ to be $90.5 \mu \mathrm{g} / \mathrm{mL}$ at $24 \mathrm{~h}$. The cell viability decreased more sharply at $48 \mathrm{~h}$, and the $\mathrm{IC}_{50}$ value was $79.5 \mu \mathrm{g} / \mathrm{mL}$. In contrast, $M$. horridula extract did not have cytotoxic effects on PBMCs $(p>0.05)$ at the used concentrations, suggesting that $M$. horrridula has some selective cell killing activity (Fig. 1B).

\section{SEM observation}

We observed the effect of M. horridula extract on L1210 cell morphology by SEM (Fig. 2 ). In the control group, cells appeared normal with a round shape, intact membrane and 


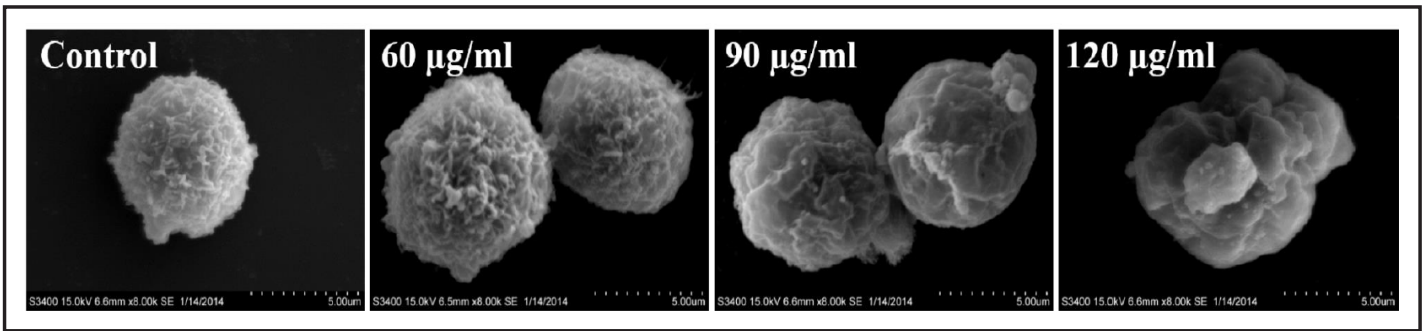

Fig. 2. SEM images of L1210 cells at $24 \mathrm{~h}$ after M. horridula extract treatment.

Fig. 3. Hoechst 33342 staining in L1210 cells after M. horridula treatment.

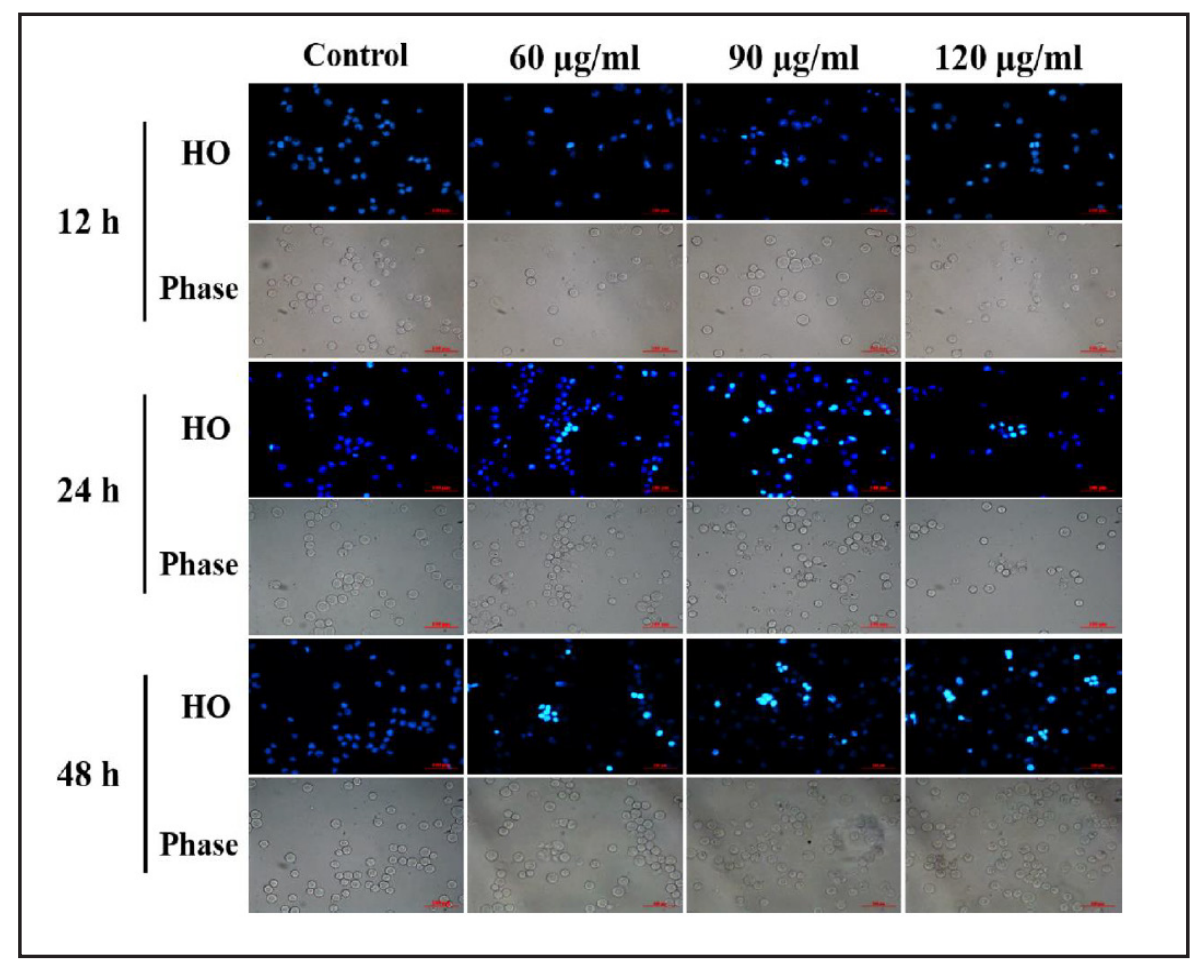

abundant microvilli. Compared to the control, cells treated with $60 \mu \mathrm{g} / \mathrm{ml}$ M. horridula were slightly changed with decreased microvilli on the cell surface. However, 90 and $120 \mu \mathrm{g} / \mathrm{ml} M$. horridula extract induced significant deformities. There was obvious structural damage on the cell surface with few microvilli remaining.

\section{M. horridula-induced nuclear damage}

The nuclear damage after different doses of $M$. horridula extract treatment was evaluated by HO staining. As shown in Fig. 3, the nuclear HO staining in control cells was slightly blue and homogeneous. However cells treated with $M$. horridula show significant morphological changes in a time-dependent manner, such as condensed chromatin and fragmented punctuate blue nuclear fluorescence. After $12 \mathrm{~h}$ of $M$. horridula incubation, the treated cells showed no obvious changes in cell morphology and nuclei comparing to the control. As the incubation time increased to 24 and $48 \mathrm{~h}$, bright blue nuclear HO fluorescence was observed in all treated cells and displays a dose-dependent manner.

\section{M. horridula extract induced apoptosis}

To determine whether M. horridula extract induced L1210 cell apoptosis, we performed Annexin V-FITC/PI double staining. As shown in Fig. 4, M. horridula extract induced L1210 cell apoptosis in a dose-dependent manner after $12 \mathrm{~h}$ incubation. The early apoptosis ratio

\section{KARGER}




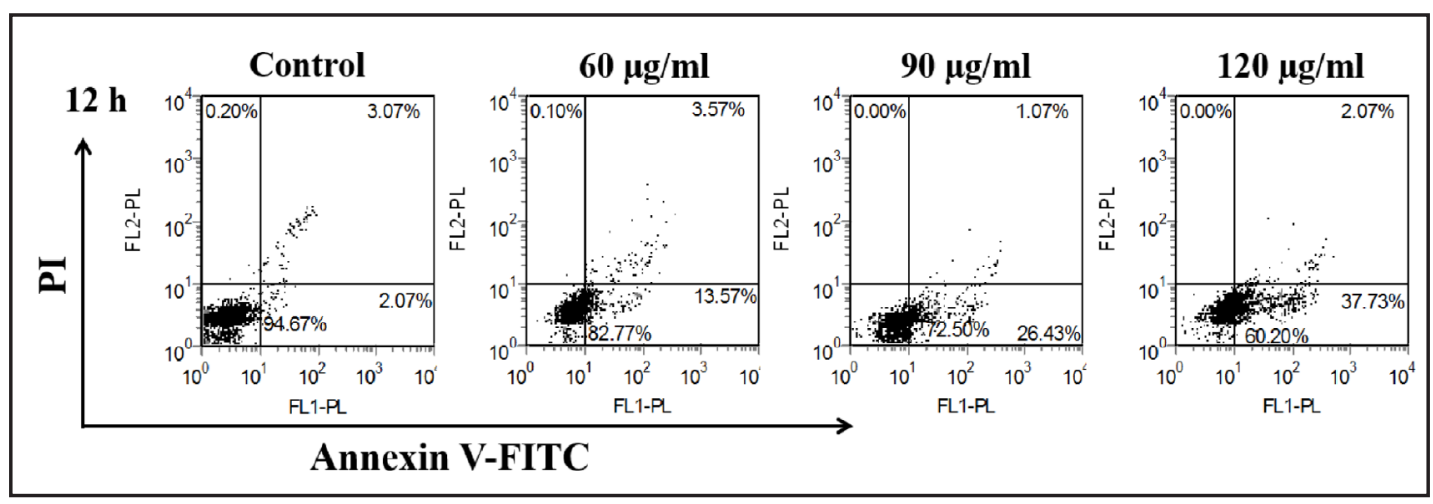

Fig. 4. M. horridula induced apoptosis in L1210 cells. Cells were double-stained with Annexin V-FITC and PI, and then analyzed by flow cytometry. All experiments were done independently in triplicate per experimental point, and representative results were shown.

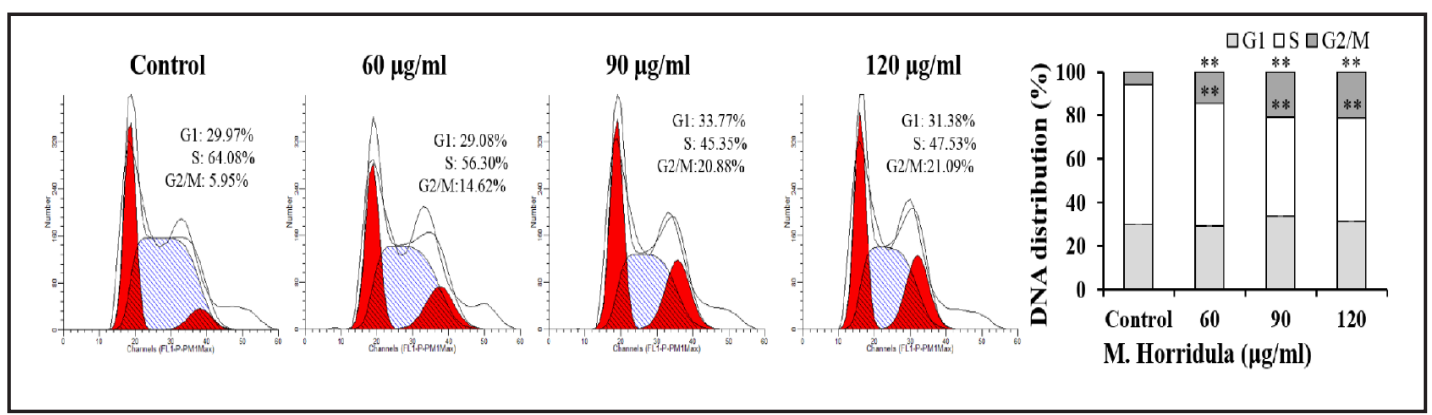

Fig. 5. Cell cycle analysis of M. horridula-treated cells. L1210 cells were harvested and fixed in 70\% alcohol and then stained with propidium iodide. The stained cells were analyzed using a flow cytometer. ${ }^{* *} \mathrm{p}<0.01$ versus control.

(lower right) increased from $13.57 \%$ to $37.73 \%$ as the concentration increased from 60 to $120 \mu \mathrm{g} / \mathrm{ml}$, while the apoptosis ratio in control group was only $2.07 \%$. The results indicate that M. horridula induced early L1210 cell apoptosis at $12 \mathrm{~h}$ after extract addition.

\section{Effect of M. horridula extract on cell cycle distribution}

Cell cycle arrest has long been regarded as a cancer treatment target. To determine whether the growth-inhibitory effect of $M$. horridula extract on L1210 cells was associated with cell cycle arrest, we analyzed the distribution of cells in different cell cycle phases by measuring intracellular DNA content. As shown in Fig. 5, M. horridula extract $(0,60,90,120$ $\mu \mathrm{g} / \mathrm{mL}$ ) treatment for $72 \mathrm{~h}$ increased the percentage of cells in the $\mathrm{G} 2 / \mathrm{M}$ phase from $5.95 \%$ to $21.09 \%$, while the proportion of cells in S phase decreased from $64.08 \%$ to $47.53 \%$ and the percentage of cells in G1 remained the same. The results indicate that M. horridula extract induced L1210 cell G2/M phase arrest in a dose-dependent manner $\left({ }^{* *} \mathrm{p}<0.01\right)$.

\section{M. horridula extract induced DNA fragmentation}

We performed PI staining with flow cytometry to evaluate $M$. horridula-induced DNA damage in L1210 cells. As shown in Fig. 6,12 h treatment of $60 \mu \mathrm{g} / \mathrm{mL}$ extract induced a 3.67-fold increase in DNA damage, but increased concentrations did not induce more severe damage. At $24 \mathrm{~h}$, DNA damage level sharply increased to 14.02-fold more than control upon $90 \mu \mathrm{g} / \mathrm{mL}$ M. horridula extract treatment. As the concentration increased to $120 \mu \mathrm{g} / \mathrm{mL}$, the DNA damage level did not further increase $(* * p<0.01)$.

\section{M. horridula treatment caused ROS accumulation}

We analyzed intracellular ROS production by flow cytometry with DCF staining. As shown in Fig. 7, M. horridula extract treatment increased intracellular ROS levels. At $2 \mathrm{~h}, M$. 


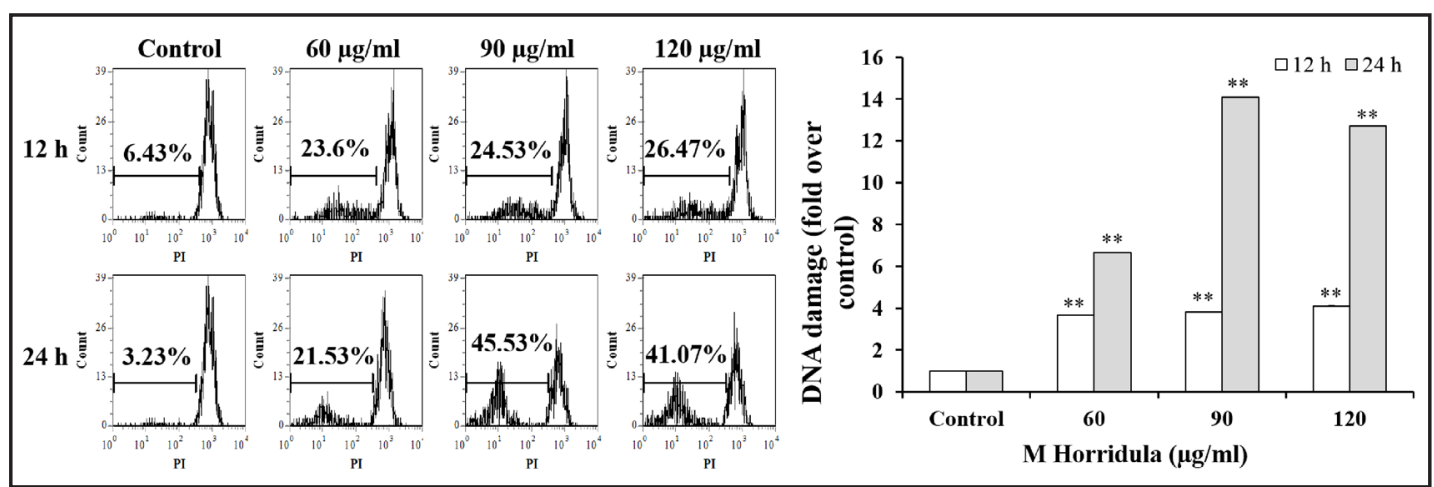

Fig. 6. Effects of M. horridula extract on DNA fragmentation of L1210 cells. Cells were treated with M. horridula extract for 12 and $24 \mathrm{~h}$, then stained with PI and analyzed by flow cytometry. Histograms show the number of cell channels (vertical axis) vs. PI fluorescence (horizontal axis). ${ }^{* *} \mathrm{p}<0.01$ versus control.

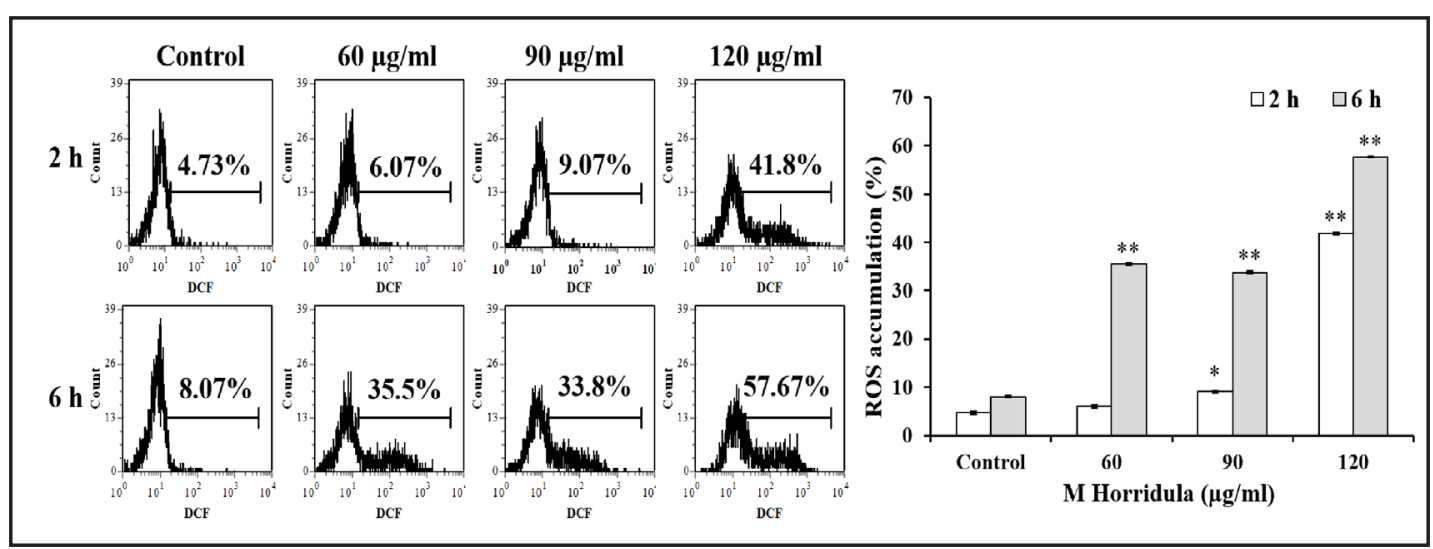

Fig. 7. ROS generation in L1210 cells after M. horridula treatment. Cells were treated with M. horridula extract for 2, $6 \mathrm{~h}$ and labeled with DCFH-DA and the fluorescence intensity of the oxidized product DCF in individual cells was detected by flow cytometry. The percentage of fluorescent cells in each group was shown. ${ }^{*} \mathrm{p}<0.05$ and ${ }^{* *} \mathrm{p}<0.01$ versus control.

horridula extract (120 $\mu \mathrm{g} / \mathrm{mL})$ treatment significantly increased ROS accumulation (41.8\%) compared to control cells (4.73\%). When the incubation time increased to $6 \mathrm{~h}$, the percentage of cells with bright DCF fluorescence significantly increased in each treatment group. The percentages of the three treated groups $(60,90$ and $120 \mu \mathrm{g} / \mathrm{mL})$ were $35.5 \%, 33.8 \%$ and $57.67 \%$, respectively, compared to $8.07 \%$ in the control sample.

\section{Discussion}

Traditional Tibetan medicine is based upon Indian medicine and traditional Chinese medicine. It continues to be practiced in Tibet, India, Nepal, Bhutan, Ladakh, Siberia, China and Mongolia, and it has been more recently practiced in parts of Europe and North America. With the rapid development of natural medicine, an increasing number of researchers have devoted themselves to studying Tibetan medicine, especially its important member- the Meconopsis species. In the present study, we tested the anticancer activity of M. horridula (belongs to the Meconopsis species) extract in vitro using the L1210 cell line.

Reports have suggested that M. horridula contains four compounds, including luteolin, apigenin, hydnocarpin and $\beta$-sitosterol [22]. However, we also previously detected quercetin, protopine, dicentrine and nonacosanol in $M$. horridula extract (data not shown). Chemical 
analyses of $M$. horridula have primarily focused on flavonoids compounds. However, botanical medicines are composed of complicated constituents, such as flavonoids, saponin and volatile compounds. Therefore, we analyzed the volatile constituents of $M$. horridula extract to identify more functional compounds in $M$. horridula. We identified 15 abundant chemicals in M. horridula extract, including Octadecadienoic acid (38.08\%), Octadecadienal (17.79\%), $\gamma$-sitosterol (7.37\%), n-Hexadecanoic acid (7.95\%). Many of these chemicals have been reported to have anticancer effects. For instance, n-Hexadecanoic acid has anti-tumor activity against human leukemic cells and murine cells [23, 24]. Essential oil composed primarily of n-Hexadecanoic acid and octadecanoic acid had significant cytotoxicity against oral cancer (KB), breast cancer (MCF-7) and small cell lung cancer (NCI-H187) [25]. Steroidal compounds showed potent growth inhibition against cancer cells [26]. Taken together, we hypothesized that the specific efficacy of such components in M. horridula results in significant anti-tumor effects. To confirm our hypothesis, we carefully investigated cell viability, ROS production, apoptosis and cell cycle arrest after M. horridula treatment.

We chose to use L1210 cells to evaluate the anticancer activity of M. horridula extract. Our results indicated that $M$. horridula extract decreased L1210 cell survival in a doseand time-dependent manner, while having little effect on normal PBMCs, suggesting that M. horridula extract may exert a selective killing effect. SEM observation showed obvious alterations on L1210 cell morphology after M. horridula treatment.

Apoptosis is a hallmark for the appraisal of potential agents for cancer prevention, and a wide variety of natural products have been known to interfere with cell proliferation or induce apoptosis [27]. The morphological characteristics of apoptosis include membrane blebbing, cell shrinkage, chromatin condensation and apoptotic body formation [28]. The results in Fig. 4 suggest that $M$. horridula primarily triggers early apoptosis of L1210 cells in a time- and dose-dependent manner. Furthermore, the presence of condensed chromatin and fragmented punctate blue nuclear fluorescence in L1210 cells confirmed apoptosis induction. DNA fragmentation is a canonical biochemical apoptotic feature. Many plants extracts have been shown to induce DNA damage [18]. Here, we found that $M$. horridula induced-apoptosis may be related to DNA damage. DNA damage often involves several signaling pathways, which can also result in cell cycle arrest and eventual apoptosis [29]. DNA damage activates P53 to induce G1 and G2/M phase arrest and apoptosis [30]. Our results suggest that $M$. horridula induces irreversible DNA damage to cause cell cycle arrest and apoptosis.

Excessive amounts of ROS can cause DNA damage, cell cycle arrest and apoptosis [31]. Although all aerobic cells are equipped with protective enzymatic and non-enzymatic antioxidants, increased oxidative stress may overwhelm the protective mechanisms, leading to cell injury [32]. Many natural compounds, such as flavonoids and triterpenoids, have been reported to increase oxidative stress by increasing intracellular ROS levels [33]. Thus, ROS are considered an important factor of natural anticancer agents. In the current study, we found that ROS accumulation preceded other changes, including DNA damage, G2 phase arrest and apoptosis, after $M$. horridula incubation, suggesting that ROS accumulation is an early event in $M$. horridula-induced cell apoptosis.

Mitochondria accumulate calcium ion upon cytosolic $\mathrm{Ca}^{2+}$ increase, leading to mitochondrial membrane depolarization [34]. Calcium ion uptake into mitochondria stimulates the tricarboxylate cycle, resulting in reduction of pyridine nucleotides, which may couple cell and metabolic oxidative stress activity [35]. Increased calcium release then induces further mitochondrial depolarization and ROS production [35]. It has been reported that a major constituent of Scutellaria wogonin induced prolonged elevation of intracellular $\mathrm{Ca}^{2+}$ levels in tumor cells, leading to ROS accumulation and eventual apoptosis [36]. In the current study, we observed that oxidative stress and cell apoptotic factors were increased in M. horridula-treated cells, suggesting that they have been caused by release of $\mathrm{Ca}^{2+}$. However, further research is required.

In conclusion, we demonstrated that M. horridula extract inhibited L1210 cell proliferation. This inhibitory effect was related to G2/M phase arrest and cell apoptosis, 
and ROS likely play an important role in the process. Our findings suggest that M. horridula extract induces L1210 cell apoptosis by increasing oxidative stress without damaging normal PBMC cells, suggesting that $M$. horridula may be a safe natural product. Further research on the tumor inhibition activities of M. horridula is required. Deep investigation into potential therapeutic targets and the compound in $M$. horridula that contributed to the anticancer activity should be carefully explored.

\section{Abbreviations}

Meconopsis horridula Hook (M. horridula ); 3-(4, 5-dimethylthiazol-2-yl)-2, 5-diphenyl tetrazolium bromide (MTT); Propidium iodide (PI); 2', 7'- dichlorodihydrofluoresceindiacetate (H2DCF-DA); Hoechst 33342 (HO), Scanning electron microscope (SEM); Gas Chromatography-Mass Spectrometer (GC-MS); Reactive oxygen species (ROS); Peripheral blood mononuclear cells (PBMCs); Heart and Umbilical Vein Endothelial (HUVE). Fetal bovine serum (FBS).

\section{Acknowledgments}

This work was supported by the National Natural Science Foundation of China (No. 81202957), and Qinghai Province (Application) Basic Research Project (No. 2013-Z-762).

\section{Disclosure Statement}

The authors declare no conflict of interest.

\section{References}

1 Lee SJ, Kim KH, Park JS, Jung JW, Kim YH, Kim SK, Kim WS, Goh HG, Kim SH, Yoo JS, Kim DW, Kim KP:

Comparative analysis of cell surface proteins in chronic and acute leukemia cell lines. Biochem Biophys Res Commun 2007;357:620-626.

2 Lim GCC: Overview of cancer in Malaysia. Jpn J Clin Oncol 2002;32:S37-42.

3 Rates SMK: Plants as source of drugs. Toxicon 2001;39:603-613.

4 Cragg GM, Newman DJ: Plants as a source of anti-cancer agents. J Ethnopharmacol 2005;100:72-79.

5 Sulaiman IMand, Hasnain SE: Randomamplified polymorphic DNA (RAPD) markers reveal genetic homogeneity in the endangered Himalayan species Meconopsis paniculata and M. simplicifolia. Theor Appl Genet 1996;93:91-96.

6 Wu C, Chuang H: A study on the taxonomic system of the genus Meconopsis. Acta Bot Yunnanica 1980;2:371-381.

7 Yang FS, Qin AL, Li YF, Wang XQ: Great Genetic Differentiation among Populations of Meconopsis integrifolia and Its Implication for Plant Speciation in the Qinghai-Tibetan Plateau. PLoS ONE 2012; 7:e37196.

8 Zhou G, Chen Y, Liu S, Yao X, Wang Y: In vitro and in vivo hepatoprotective and antioxidant activity of ethanol extract from Meconopsis integrifolia (Maxim.) Franch. J Ethnopharmacol 2013;148:664-670.

9 Samant SS: Diversity, endemism and socio-economic values of the Indian Himalayan Papaveraceae and Fumariaceae. J Indian Bot Soc 2005;84:33-44.

10 Zhao Y, Zhang SB, Yang J, Zhang L: Characterization of 13 microsatellite loci developed from Meconopsis horridula. Genet Mol Biol 2010;33:539-541.

11 Wu HF, Ding LS, Wang H, Zhang XF: Advances in the research of phytochemistry and pharmacology of meconopsis vig. Nat Prod Res Dev 2011;23:163-168.

12 Li SK: Preliminary study on antenatal diagnosis of cytomegalovirus infection by polymerase chain reaction (PCR) technique. Zhong hua Fu Chan Ke Za Zhi 1993;28:130-132.

13 Liu J, Wu H, Zheng F, Liu W, Feng F, Xie N: Chemical constituents of Meconopsis horridula and their simultaneous quantification by high-performance liquid chromatography coupled with tandem mass spectrometry. Science 2014;37:2513-2522. 
14 Wu HF, Pan L, Zou DS, Yang SJ, Zhang XF: Analysis on volatile oils from three species of Meconopsis by GCMS. Chin Pharm 2006;41:1298-1300.

15 Thompson CB: Apoptosis in the pathogenesis and treatment of disease. Science 1995;267:1456-1462.

16 Kerr JF, Winterford CM, Harnon BV: Apoptosis-its significance in cancer and cancer therapy. Cancer 1994;73:2013-2026.

17 Symonds H, L Krall, L Remington, M Saenz-Robles, S Lowe, T Jacks, T Van Dyke: p53-dependent apoptosis suppresses tumor growth and progression in vivo. Cell 1994;78:703-711.

18 Wang Y, Cheng X, Wang P, Wang L, Fan J, Wang X. Liu Q: Investigating Migration Inhibition and Apoptotic Effects of Fomitopsis pinicola Chloroform Extract on Human Colorectal Cancer SW-480 Cells. PLoS ONE 2014;9:e101303.

19 Shi X, Zhao Y, Jiao Y, Shi T, Yang X: ROS-Dependent Mitochondria Molecular Mechanisms Underlying Antitumor Activity of Pleurotus abalonus Acidic Polysaccharides in Human Breast Cancer MCF-7 Cells. PLoS ONE 2013;8:e64266.

20 Tanaka S, Koyama S, Haniu H, Yamaguchi Y, Motoyoshiya J: In vitro and in vivo antitumor activity of YoshixolTR against murine L1210 leukemic cells. Gen Pharmacol 1999;33:179-186.

21 Krysko DV, Vanden Berghe T, D'Herde K, Vandenabeele P: Apoptosis and necrosis: detection, discrimination and phagocytosis. Methods 2008;44:205-221.

22 Liu J, Wu H, Zheng F, Liu W, Feng F, Xie N: Chemical constituents of Meconopsis horridula and their simultaneous quantification by high-performance liquid chromatography coupled with tandem mass spectrometry. J Sep Sci 2014;37:2513-2522.

23 Semary NAE, Ghazy SM, Naby MMAE: Investigating the taxonomy and bioactivity of an Egyptian Chlorococcum isolate. Aust J Basic Appl Sci 2009;3:1540-1551.

24 Harada H, Yamashita U, Kurihara H, Fukushi E, Kawabata J, Kamei Y: Antitumor activity of palmitic acid found as a selective cytotoxic substance in a marine red alga. Anticancer Res 2002;22:2587-2590.

25 Keawsa-ard S, Liawruangrath B, Liawruangrath S, Teerawutgulrag A, Pyne SG: Chemical constituents and antioxidant and biological activities of the essential oil from leaves of Solanum spirale. Nat Prod Commun 2012;7:955-958.

26 Zhao YY, Shen X, Chao X, Ho CC, Cheng XL, Zhang Y, Lin RC, Du KJ, Luo WJ, Chen JY, Sun WJ: Ergosta-4, 6, 8(14), 22-tetraen-3-one induces G2/M cell cycle arrest and apoptosis in human hepatocellular carcinoma HepG2 cells. Biochim Biophys Acta 2011;4:384-390.

27 Taraphdar AK: Natural products as inducers of apoptosis: Implication for cancer therapy and prevention. Curr Sci 2001;80:1387-1396.

28 Rello S, Stockert JC, Moreno V, Gámez A, Pacheco M, Juarranz A, Cañete M, Villanueva A: Morphological criteria to distinguish cell death induced by apoptotic and necrotic treatments. Apoptosis 2005;10:201208.

29 Leventis PA, Grinstein S: The distribution and function of phosphatidylserine in cellular membranes. Annu Rev Biophys 2010;39:407-427.

30 He N, Shi X, Zhao Y, Tian L, Wang D, Yang X: Inhibitory effects and molecular mechanisms of seleniumcontaining tea polysaccharides on human breast cancer MCF-7 cells. J Agric Food Chem 2013;61:579-588.

31 Naziroğlu M, Uğuz AC, Koçak A, Bal R: Acetaminophen at different doses protects brain microsomal Ca2+ ATPase and the antioxidant redox system in rats. J Membr Biol 2009;231:57-64.

32 Guney M, Ozguner F, Oral B, Karahan N, Mungan T: 900 MHz radiofrequency-induced histopathologic changes and oxidative stress in rat endometrium: protection by vitamins $\mathrm{E}$ and $\mathrm{C}$. Toxicol Ind Health 2007;23:411-420.

33 Q Huang, G Lu, HM Shen, MC Chung, CN Ong: Anti-cancer properties of anthraquinones from rhubarb. Med Res Rev 2007;27:609-630.

34 Uguz AC, Cig B, Espino J, Bejarano I, Naziroglu M, Rodríguez AB, Pariente JA: Melatonin potentiates chemotherapy-induced cytotoxicity and apoptosis in rat pancreatic tumor cells. J Pineal Res 2012;53:9198.

35 Kovács R, Kardos J, Heinemann U, Kann O: Mitochondrial calcium ion and membrane potential transients follow the pattern of epileptiform discharges in hippocampal slice cultures. J Neurosci 2005;25:4260-4269.

36 Baumann S, Fas SC, Giaisi M, Müller WW, Merling A, Gülow K, Edler L, Krammer PH, Li-Weber M: Wogonin preferentially kills malignant lymphocytes and suppresses T-cell tumor growth by inducing PLCgamma1and Ca2+-dependent apoptosis. Blood 2008;111:2354-2363. 